\title{
Adsorption of Organophosphate Pesticide Dimethoate on Gold Nanospheres and Nanorods
}

\author{
Tatjana Momić,' Tamara Lazarević Pašti, ${ }^{1}$ Una Bogdanović, ${ }^{1}$ Vesna Vodnik, \\ Ana Mraković, ${ }^{1}$ Zlatko Rakočević, ${ }^{1}$ Vladimir B. Pavlović, ${ }^{2}$ and Vesna Vasić ${ }^{1}$ \\ ${ }^{1}$ Institute of Nuclear Sciences Vinča, University of Belgrade, P.O. Box 522, 11001 Belgrade, Serbia \\ ${ }^{2}$ Faculty of Agriculture, University of Belgrade, P.O. Box 127, 11080 Zemun, Serbia \\ Correspondence should be addressed to Tatjana Momić; momict@vinca.rs
}

Received 21 July 2016; Revised 28 September 2016; Accepted 10 October 2016

Academic Editor: Jorge Pérez-Juste

Copyright (C) 2016 Tatjana Momić et al. This is an open access article distributed under the Creative Commons Attribution License, which permits unrestricted use, distribution, and reproduction in any medium, provided the original work is properly cited.

\begin{abstract}
Organophosphorus pesticide dimethoate was adsorbed onto gold nanospheres and nanorods in aqueous solution using batch technique. Adsorption of dimethoate onto gold nanoparticles was confirmed by UV-Vis spectrophotometry, TEM, AFM, and FTIR analysis. The adsorption of nanospheres resulted in aggregation which was not the case with nanorods. Nanoparticles adsorption features were characterized using Langmuir and Freundlich isotherm models. The Langmuir adsorption isotherm was found to have the best fit to the experimental data for both types of nanoparticles. Adsorption capacity detected for nanospheres is $456 \mathrm{mg} / \mathrm{g}$ and for nanorods is $57.1 \mathrm{mg} / \mathrm{g}$. Also, nanoparticles were successfully used for dimethoate removal from spiked drinking water while nanospheres were shown to be more efficient than nanorods.
\end{abstract}

\section{Introduction}

Organophosphorus pesticides (OPs) are commonly used in agriculture [1]. Dimethoate (Scheme 1) as one of the major OPs is widely used in the fruit and field crops to promote the development of agricultural production because of its low persistence and biodegradation [2]. Still, extreme use of dimethoate could lead to excessive residues accumulating in the environment and in human body through the food chain and could cause death $[3,4]$. For these reasons, there is the necessity of the efficient removal of OPs in order to control the levels of these compounds in food and the environment, especially drinking water resources.

One of the main strategies for removal of pesticides from water is the adsorption on different types of materials [5]. Numerous studies can be found in the literature reporting OPs adsorption on mineral surfaces [6,7], carbon-based materials [8-10], and materials from graphene family [11]. Nowadays, application of nanoparticles (NPs) in environmental remediation such as water purification by removal of OPs is significantly progressing because of nanomaterial chemistry advantages with respect to conventional technologies $[1,12]$. NPs owe their potential to the high active surface area and surface reactivity compared to conventional bulk materials $[5,13]$. Noble metal, mainly silver and gold, nanostructures have been used for water purification particularly because the chemistry occurs at room temperature and, with high efficiency, the chemical procedures involved are simple, so they can adsorb the pesticide molecules with ease which is making this process highly practical $[1,5]$. Nanosilver and nanogold bioconjugate synthesized on the surface of fungal strain Rhizopus oryzae were used for removal of various organophosphate pesticides $[14,15]$. It was shown that silver and gold nanospheres, bare and supported on alumina, adsorb organophosphorous pesticides chlorpyrifos and malathion. These features of nanoparticles present a convenient and cost-effective system for the removal of pesticides from drinking water $[1,16]$. Gold is not cheap material and still it possesses properties as robustness and unique spectral characteristics. The spectral characteristics of gold nanoparticles are more pronounced than those of their silver counterparts. The change in dielectric constant 


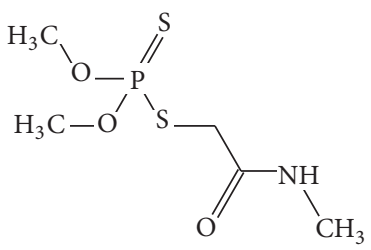

SCHEME 1: Dimethoate.

of silver upon pesticide binding which is less compared to that of gold $[1,16]$ gives the gold advantage over silver or some cheaper metal nanomaterials. Nair and Pradeep supported gold nanoparticles on alumina and made online water filter to demonstrate technology of OPs removal from water in rural communities in India [17]. Moreover, water purification from an environmental perspective by using gold-poly(dimethylsiloxane) nanocomposite in the form of a foam was described [18].

Rod-shape nanoparticles possess several advantages over the nanospheres, such as high surface area and good electron mediation capability [19-21]. However, to date, to the best of our knowledge the use of gold nanorods for adsorption of OP dimethoate has not been reported. In this contribution, we considered gold nanoparticles of two different shapes nanospheres (NSs) and nanorods (NRs) as adsorbents of dimethoate from aqueous solutions. The aim of our study was to characterize the interaction between dimethoate and gold nanorods. NSs and NRs have different physical and chemical properties, so the effects of these properties on their performance as adsorbents are discussed. We have also compared direct uses of investigated NPs for removal of dimethoate from drinking water.

\section{Experimental}

2.1. Chemicals and Materials. All the chemicals used were purchased from Sigma Aldrich Co., St. Louis, MO. 400-mesh $\mathrm{Cu}$ grid coated in a thin layer of carbon was purchased from Ted Pella, Inc., Redding, CA. MICA was purchased from SPI Supplies, West Chester, PA. Milli-Q deionized water used had 18.2 $\mathrm{M} \Omega$ electrical resistivity.

\subsection{Synthesis of Gold Colloids}

2.2.1. Synthesis of Gold Nanospheres. Colloidal dispersion of gold nanospheres (AuNSs) was prepared using a reduction of precursor salt $\left(\mathrm{HAuCl}_{4}\right)$ solution by sodium citrate, as described elsewhere $[22,23]$. In a typical synthesis, $200 \mathrm{~mL}$ of $1 \mathrm{mM} \mathrm{HAuCl}_{4}$ solution was stirred and heated in a roundbottom flask, fitted with a reflux condenser. After the solution reached the boiling point, $10 \mathrm{~mL}$ of $38.8 \mathrm{mM}$ sodium citrate was rapidly added. The colloidal dispersion was boiled and stirred for additional $15 \mathrm{~min}$ and then cooled down to room temperature with continuous stirring. The final concentration of $\mathrm{Au}$ in colloidal dispersion was found to be $0.91 \mathrm{mM}$ $(179 \mathrm{mg} / \mathrm{L})$.

2.2.2. Synthesis of Gold Nanorods. Colloidal dispersion of gold nanorods (AuNRs) was prepared using a seed-mediated growth approach [24]. Colloidal gold seed solution was first prepared as follows: $5 \mathrm{~mL}$ of $200 \mathrm{mM} \mathrm{CTAB}$ solution was added to $5 \mathrm{~mL}$ of $0.5 \mathrm{mM} \mathrm{HAuCl}{ }_{4}$ solution. Next, $0.6 \mathrm{~mL}$ of ice-cold $10 \mathrm{mM} \mathrm{NaBH}_{4}$ (reducing agent) solution was injected into the yellow solution all at once while stirring vigorously. Stirring was stopped after $2 \mathrm{~min}$. The color of seed solution was changed to brownish-yellow and was stable for 2 hours. In the next step, the stock solution was prepared as follows: $0.25 \mathrm{~mL}$ of $4 \mathrm{mM} \mathrm{AgNO}$ solution was added to $5 \mathrm{~mL}$ of $200 \mathrm{mM} \mathrm{CTAB}$ solution and gently mixed in order to add $5 \mathrm{~mL}$ of $1 \mathrm{mM} \mathrm{HAuCl}_{4}$ solution. All solutions, other than those of gold and CTAB, were prepared fresh daily. The yellow stock solution became colorless, after adding $70 \mu \mathrm{L}$ of $78.8 \mathrm{mM}$ ascorbic acid. Thereafter, $10 \mu \mathrm{L}$ of seed solution was added to the stock solution. CTAB solution crystallizes at $25^{\circ} \mathrm{C}$ so colloid was synthesized in the temperature range from $27^{\circ} \mathrm{C}$ to $30^{\circ} \mathrm{C}$ to ensure proper nanorods growth. A violet-blue color appeared within $15-20 \mathrm{~min}$. Rods were concentrated and separated from spheres and surfactant by centrifugation (10000 rpm for $15 \mathrm{~min}$ ). After centrifuging, the surfactant was removed and the precipitate was further redispersed in deionized water. The final concentration of $\mathrm{Au}$ in colloidal dispersion was found to be $0.01 \mathrm{mM}(2 \mathrm{mg} / \mathrm{L})$.

2.3. Characterization of AuNPs and Their Dimethoate Conjugates. The NPs interactions with dimethoate were characterized using UV-Visible (UV-Vis) spectroscopy (Lambda 35 UV-Vis Spectrometer, Perkin Elmer, Inc., Waltham, MA, USA). All spectra were background-subtracted against deionized water, which is the reaction solvent. Over a period of 24 hours, spectra were recorded. Transmission electron microscope (TEM) images of the NPs and NPs-dimethoate assembly were obtained using TEM, JEOL JEM-1400 (Jeol Ltd., Tokyo, Japan) operated at $120 \mathrm{kV}$. A total of $5 \mu \mathrm{L}$ of the reaction solution was pipetted onto the surface of a 400 -mesh $\mathrm{Cu}$ grid coated in a thin layer of carbon and allowed to dry on the air. Atomic force microscopic (AFM) images of AuNPs in the absence and presence of dimethoate were recorded using Multimode Quadrex SPM with Nanoscope IIIe controller (Veeco Instruments, Inc., Camarillo, CA), at room temperature, using AFM-FM technique and force modulation probe holder with a piezoelectric bimorph and a commercial Veeco FESP probe with a cantilever. Mica substrates were prepared for imaging as follows. Freshly cleaved mica was modified with a $100 \mu \mathrm{L}$ deposit of $0.01 \% 3$-(aminopropyl)triethoxysilane (APTES) solution. After a 20 min incubation period, the mica surface was rinsed six times with $1 \mathrm{~mL}$ aliquots of water and dried with compressed nitrogen [25]. A drop of $10 \mu \mathrm{L}$ suspension of AuNPs without and with dimethoate was deposited on mica surface and incubated for $30 \mathrm{~min}$, followed by repeated washing with deionized water to remove any unbound materials and dried in air for AFM measurements [26]. Fourier transform infrared (FTIR) spectra of dimethoate as well as dimethoate in the presence of $\mathrm{Au}$ nanoparticles were recorded on Nicolet IS $50 \mathrm{FT}$ IR Spectrometer (Thermo Fisher Scientific, Waltham, MA, USA). Samples were prepared by dripping the solution on glass slides and left to dry on the air. Samples were analyzed at ambient conditions in the mid-IR region $\left(400-4000 \mathrm{~cm}^{-1}\right)$. 
Nicolet IS 50 FT-IR Spectrometer was operating in the ATR mode and measuring resolution was $4 \mathrm{~cm}^{-1}$ with 32 scans.

2.4. Batch Adsorption Experiments. The adsorption experiments were performed via the batch technique in aqueous solution at $\mathrm{pH} 5.7$, at the temperature of $25^{\circ} \mathrm{C}$, for 24 hours of shaking. Adsorption of dimethoate onto gold nanoparticles was done under various conditions such as adsorbent dosage $(2-200 \mathrm{mg} / \mathrm{L})$ and initial dimethoate concentration $(2-1150 \mathrm{mg} / \mathrm{L})$. Samples were centrifuged at $14000 \mathrm{rpm}$ for 20 min and measurement of dimethoate remaining concentration in the solution was done using Waters ACQUITY Ultraperformance Liquid Chromatography (UPLC) ${ }^{\mathrm{TM}}$ system coupled with a TUV detector controlled by the Empower software. Chromatographic separations were run on an ACQUITY UPLC BEH $\mathrm{C}_{18}$, column $1.7 \mu \mathrm{m}, 100 \mathrm{~mm} \times$ $2.1 \mathrm{~mm}$ column (Waters, Milford, MA, USA). The analyses of dimethoate were done under isocratic conditions with mobile phase consisting of $10 \%$ acetonitrile and $90 \%$ water $(\mathrm{v} / \mathrm{v})$. The elutions were monitored at $230 \mathrm{~nm}$. The eluent flow rate was $0.2 \mathrm{~mL} \mathrm{~min}^{-1}$ and the injection volume was $10 \mu \mathrm{L}$ [10]. The amount of dimethoate adsorbed onto gold nanoparticles at equilibrium, adsorption capacity $q_{e}(\mathrm{mg} / \mathrm{g})$, was calculated by the following relationship [27]:

$$
q_{e}=\frac{V\left(c_{0}-c_{e}\right)}{W},
$$

where $c_{e}$ is the equilibrium concentration of dimethoate $(\mathrm{mg} / \mathrm{L}), V$ is the volume of the solution $(\mathrm{L})$, and $W$ is the weight of the gold nanoparticles as an adsorbent (mg). In all experiments the volume of the solution was $1 \mathrm{~mL}$.

\section{Results and Discussion}

3.1. Spectrophotometric Analysis of AuNPs and Their Conjugates. Adsorption of dimethoate on gold nanoparticles (spheres and rods) was first followed spectrophotometrically. Figure 1 shows the changes in the absorption spectra of gold nanoparticles upon exposure to $0.5 \times 10^{-3} \mathrm{M}$ dimethoate for 24 hours. All the experiments were repeated at least three times with another set of AuNPs, and the results were reproducible. Trace A in Figure 1(a) is the absorption spectrum of citrate-capped Au nanospheres with absorption maximum at $524 \mathrm{~nm}$ and trace B was taken immediately after the addition of dimethoate to nanosphere solution. The subsequent traces were taken at 20-minute interval time up to 5 hours. The next two traces $C$ and $D$ were recorded after 12 and 24 hours, respectively. As can be seen from the spectra, surface plasmon resonance (SPR) band of AuNSs at $524 \mathrm{~nm}$ after mixing with dimethoate decreased in intensity and new broad absorption peak emerged at longer wavelength. The absorption intensity of the new absorption peak increased with time, accompanied with further red shift (Figure 1(a)). The reduction of the intensity of the original surface plasmon and the appearance of a broad absorption at longer wavelengths noticed in the first 5 hours are attributed to the aggregation of NSs. Aggregation occurred due to replacement of citrate anions on the surface of AuNS with dimethoate which consequently reduced the surface charges of the AuNPs [28]. Because of the high affinity of the sulphur group for gold, dimethoate as sulphur-containing ligand was able to replace the citrate anions on the AuNS surface [29].

The spectrum of NSs incubated with dimethoate for 24 hours was the same as the spectrum of bare AuNSs (Figure $1(\mathrm{a})$, trace $\mathrm{D})$. This change indicated that the electrostatically attached citrate molecules have been completely replaced by a more stable and covalently bound surface functionalization [30-32]. Replacing citrate by the sulphur-containing ligands increases the stability of nanogold solutions [33]. The same pattern of nanogold stabilization was noticed after 24 hours of their incubation with different concentrations of dimethoate (Figure 2(a)). The highest stabilization of NSs was noticed with $1 \times 10^{-2} \mathrm{M}$ dimethoate, the highest concentration used.

Trace A in Figure 1(c) represents the absorption spectrum of CTAB-capped $\mathrm{Au}$ nanorods with two plasmon peaks, the dominant one at $765 \mathrm{~nm}$ attributed to the surface plasmon resonance along longitudinal direction and peak at $520 \mathrm{~nm}$ that represents the surface plasmon resonance along transverse direction. Trace B was taken immediately after the addition of dimethoate to nanorods solution. All the subsequent traces were taken at 20-minute intervals time up to 5 hours. The next two traces $\mathrm{C}$ and $\mathrm{D}$ were recorded after 12 and 24 hours, respectively. It was noticed that absorption peaks at $765 \mathrm{~nm}$ and $520 \mathrm{~nm}$ decreased in intensities while only absorption maximum at $756 \mathrm{~nm}$ blue shifted. Regarding the fact that no red shift of longitudinal SRP was observed which indicates no side-to-side nanorods interaction and even though blue shift occurred but not corresponding growth of band at $520 \mathrm{~nm}$ there are no indication of end-toend nanorods interaction. Moreover, we observe that after 24 hours of nanorods incubation with dimethoate the width of the bands was constant (Figure 1(c), trace D), indicating a good dispersion of the nanoparticles in the solution which confirmed that no aggregation occurred [34-36]. The same behavior of NRs was noticed after 24 hours of their incubation with different concentrations of dimethoate (Figure 2(b)). As expected, positions of LSRP bands vary as a function of pesticide concentration. Since red shift was not observed, we can conclude that NRs did not aggregate. As dimethoate is neutral compound, stable in acid to neutral conditions with one sulphur atom accessible for interaction, while CTABcapped nanorods are positively charged, we suppose that dimethoate can only weakly adsorb on the CTAB double layer through electrostatic forces and not on the AuNRs' surface. Moreover, as the CTAB is preferentially bound onto lateral facets of nanorods, leaving the ends uncoated [35], there is a probability for the dimethoate to covalently bind on the nanorod ends. These changes of the AuNRs environment could explain LSRP slight blue shift (Figure 1(b)).

Since the changes in the characteristic SPR bands in both NPs solutions in the presence of dimethoate were recorded for 24 hours, the kinetics of NPs interaction with dimethoate are depicted in Figures 1(b) and 1(d). Results in the figures represent the change of absorbance at 524 and $720 \mathrm{~nm}$ for AuNSs and at 520 and $765 \mathrm{~nm}$ for AuNRs in time. The shape of the kinetic curves clearly indicates that the spectral changes follow at least two processes in both cases. The fast process, 


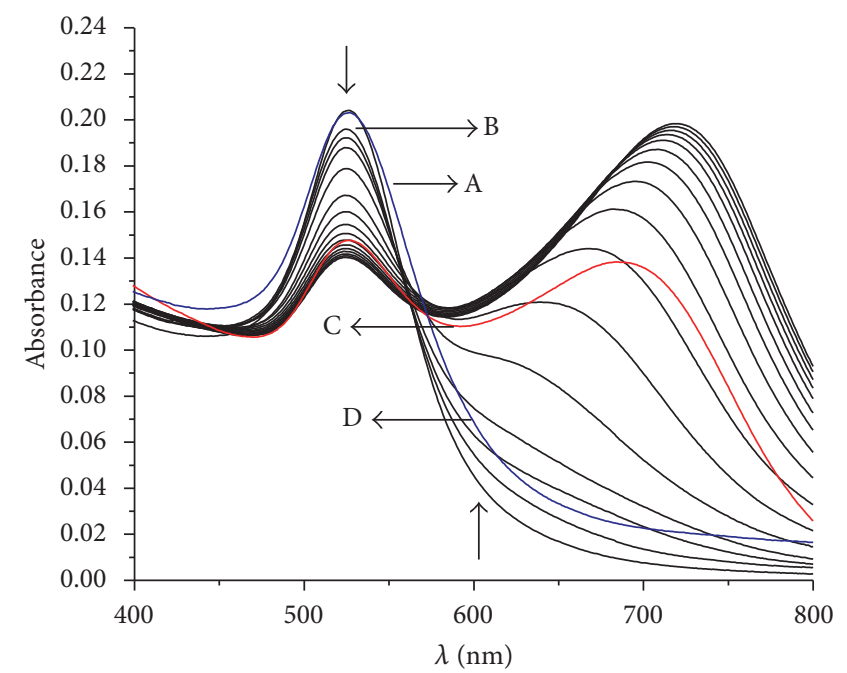

(a)

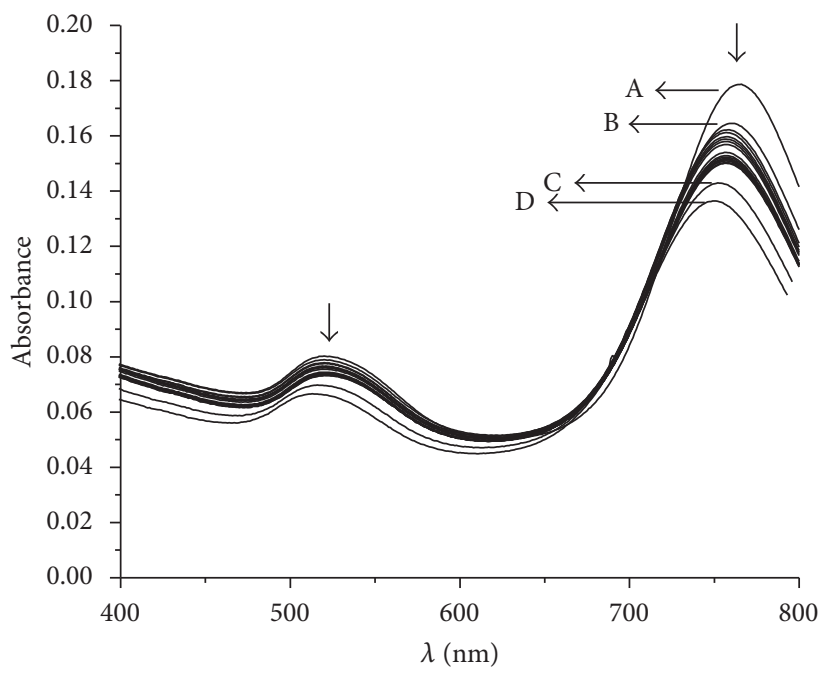

(c)

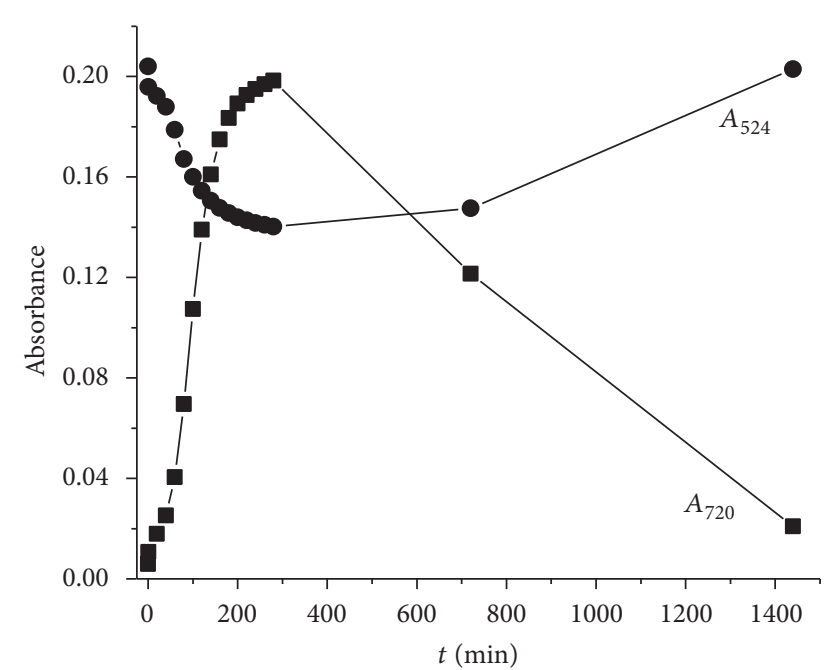

(b)

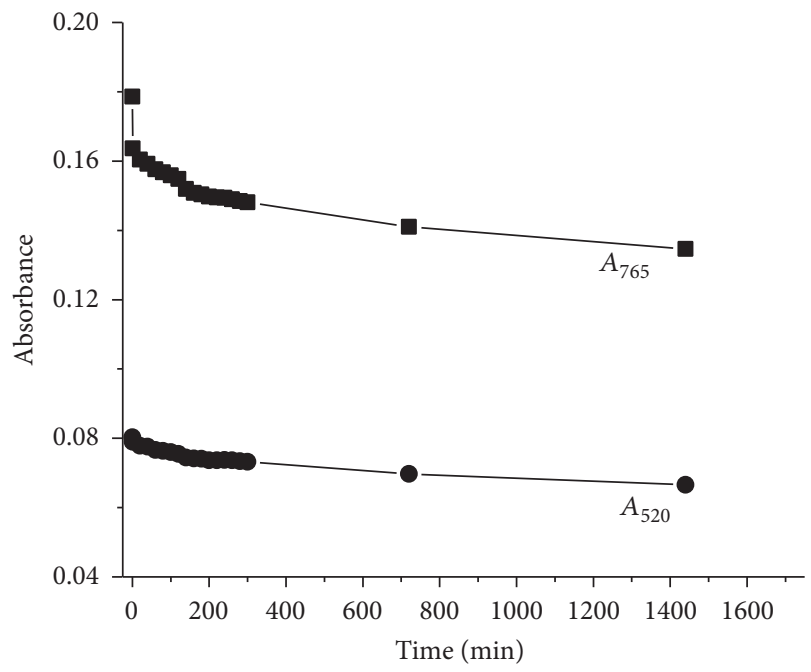

(d)

FIgURE 1: The time dependent UV-Visible spectra showing the absorption of dimethoate on (a) AuNSs and (c) AuNRs. Traces A are the absorption spectra of bare NPs, traces B were taken immediately after addition of $0.5 \times 10^{-3} \mathrm{M}$ dimethoate to NPs solutions, and each following trace was taken after $20 \mathrm{~min}$. Traces C and D were taken after 12 and 24 hours, respectively. The scans were taken for 24 hours. Time dependence of dimethoate adsorption on (b) NSs measured at $524 \mathrm{~nm}$ and $720 \mathrm{~nm}$ and (d) NRs measured at $520 \mathrm{~nm}$ and $765 \mathrm{~nm}$.

which occurs within a few seconds after mixing of dimethoate with NSs suspension, can be ascribed to the sorption of OP on NSs' surfaces (Figure 1(b), $A_{524}$ ). The next phase indicates that the aggregation of functionalized NSs occurs, followed by the drastic changes of absorption band at $524 \mathrm{~nm}$. The last phase shows the increase of $524 \mathrm{~nm}$ band intensity, characteristic of stable AuNPs suspension. These phases are also very well recognized by spectral changes of absorption band at $720 \mathrm{~nm}$ (Figure 1(b), $A_{720}$ ).

The spectral changes of NRs characteristic bands at $765 \mathrm{~nm}$ and $520 \mathrm{~nm}$ presented in Figure 1(d) indicated the fast process of dimethoate adsorption onto AuNRs which occurred in a few seconds. The spectral changes that followed in the second phase indicated reaching of equilibrium. No further changes of the bands intensity were noticed till the end of the incubation period.
3.2. TEM Analysis. In order to determine the dimension of synthesized nanoparticles in the absence and presence of dimethoate, TEM was performed. The average particle diameter of citrate-capped nanospheres obtained from TEM measurements is $26.6 \pm 5.5$ (Figure $3(\mathrm{a})$ ) while the CTABcapped nanorods length is $45.4 \pm 6.9$ with diameter $15.9 \pm 2.4$, with an average aspect ratio of 2.5 (Figure 3(c)). After addition of $0.5 \times 10^{-3} \mathrm{M}$ dimethoate in nanoparticles solutions and 24 hours of their incubation, the TEM images indicated that there were no changes in the NPs shape and size (Figures 3(b) and $3(\mathrm{~d})$ ).

3.3. AFM Analysis. To record structural and morphological changes of AuNPs before and after their 24 hours of incubation with $0.5 \times 10^{-3} \mathrm{M}$ dimethoate, AFM study was conducted. The tapping mode dissemination images of bare AuNSs and 


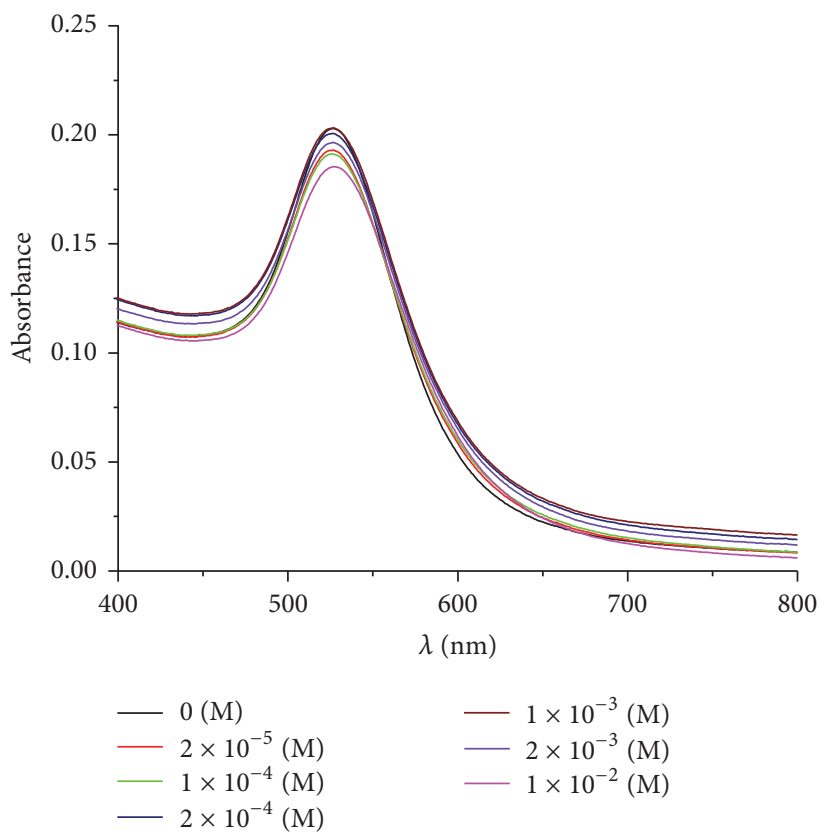

(a)
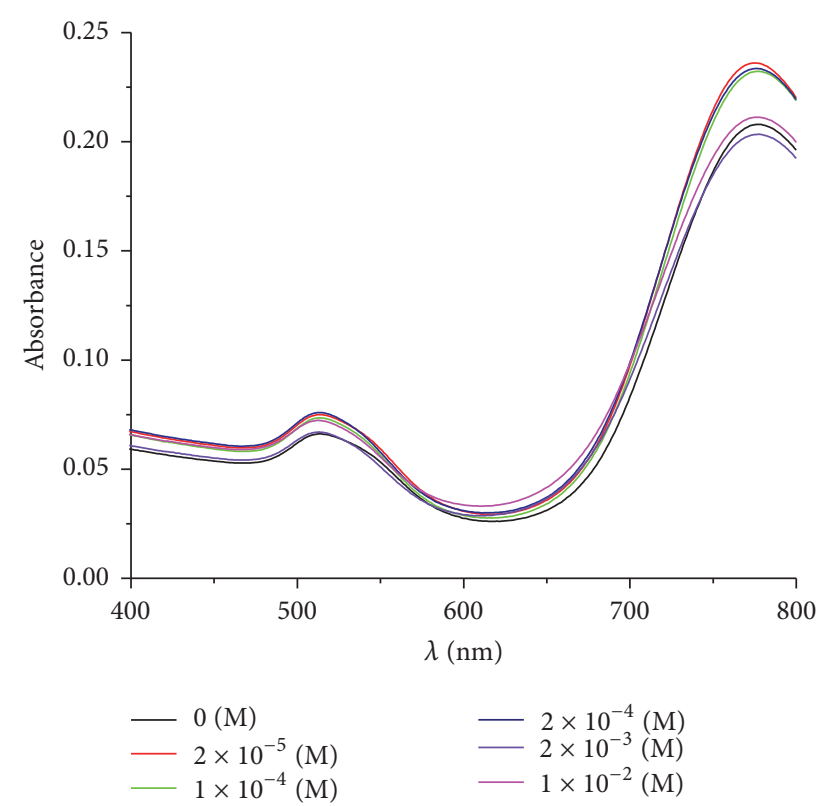

(b)

FIgURE 2: Absorption spectra of (a) AuNSs and (b) AuNRs upon 24 hours of incubation with different concentrations of dimethoate.

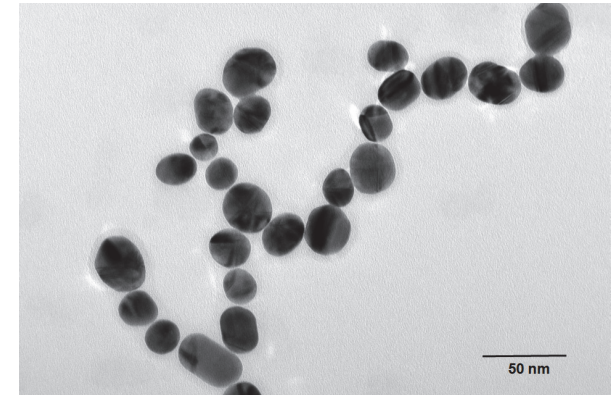

(a)

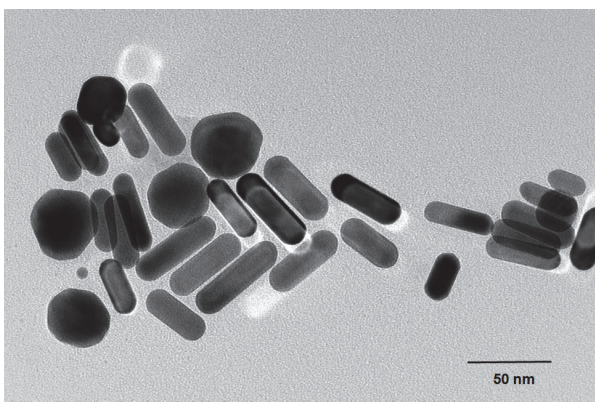

(c)

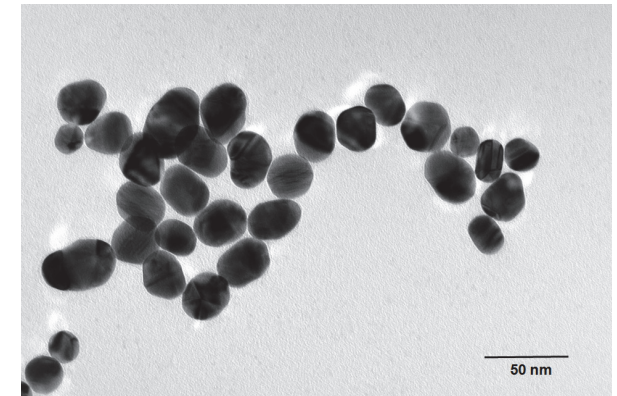

(b)

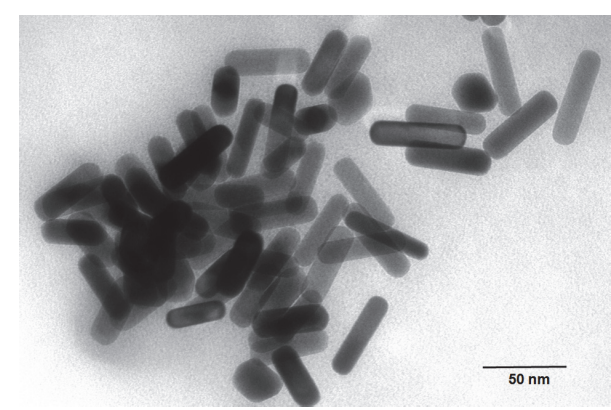

(d)

Figure 3: TEM images of (a) AuNSs, (b) AuNSs treated with dimethoate, (c) AuNRs, and (d) AuNRs treated with dimethoate.

AuNRs were presented in Figures 4(a) and 4(b), respectively. The diameter of citrate-capped nanospheres obtained by AFM measurements is $32.4 \pm 6.8$, while the CTAB-capped nanorods length is $43.7 \pm 5.2$ with diameter $19.8 \pm 3.4$. These dimensions correlate with the size of NPs measured by TEM. Figures 4(c) and 4(d) show the representative images of
AuNSs and AuNRs, respectively, after their incubation with dimethoate.

3.4. FTIR Analysis. To understand the involvement of the active groups of dimethoate in its adsorption to AuNP surfaces, FTIR spectra were recorded. The FTIR spectrum 


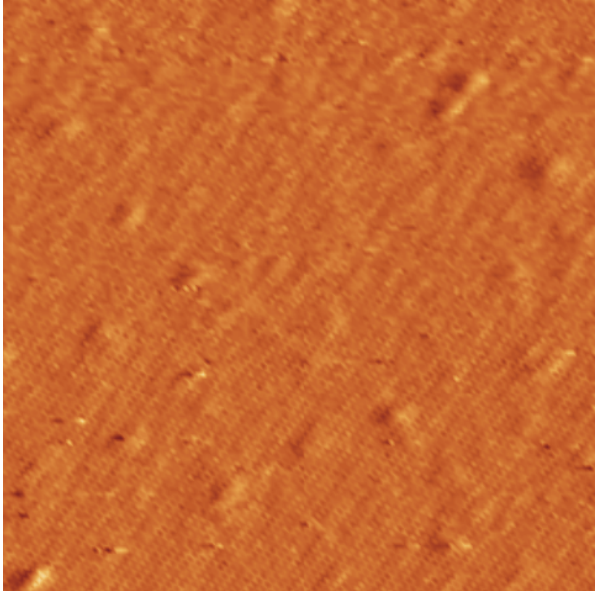

(a)

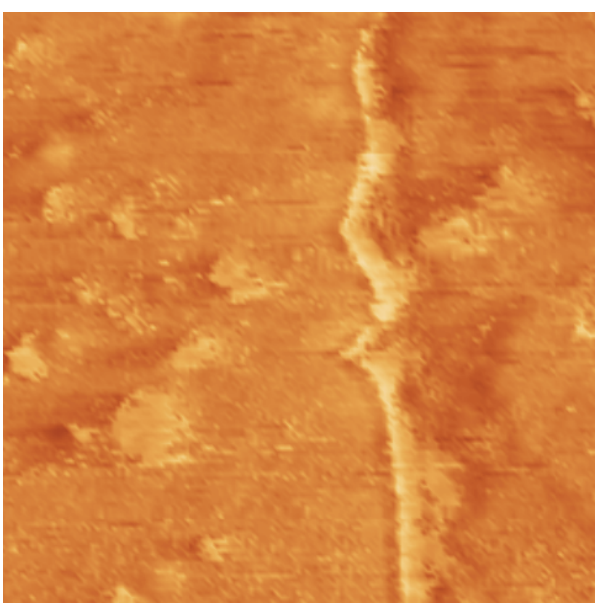

(c)

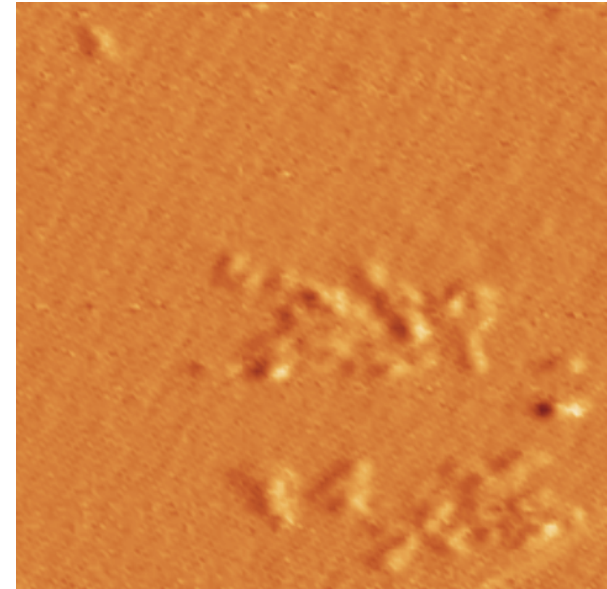

(b)

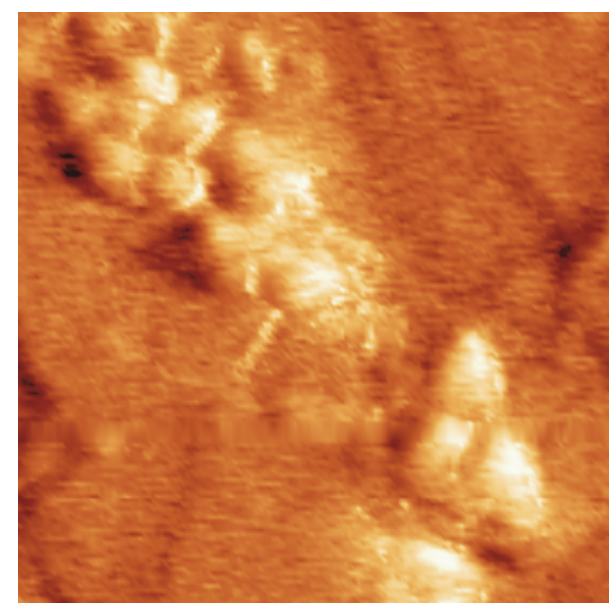

(d)

FiguRE 4: AFM images (scan area $1.0 \mu \mathrm{m} \times 1.0 \mu \mathrm{m}$ ) of (a) bare AuNSs and (b) AuNSs treated with dimethoate, (c) bare AuNRs, and (d) AuNRs treated with dimethoate.

of dimethoate (Figures 5(a)(A) and 5(b)(A)) shows bands at $1641 \mathrm{~cm}^{-1}$ and $1565 \mathrm{~cm}^{-1}$, corresponding to amide $\mathrm{I}(\mathrm{C}=\mathrm{O}$ and $\mathrm{C}-\mathrm{N}$ stretching vibrations) and amide II (mixed vibration of $\mathrm{N}-\mathrm{H}$ deformation and $\mathrm{C}-\mathrm{N}$ stretch) bands, respectively [37]. Also, two peaks appearing at $2841 \mathrm{~cm}^{-1}$ and $2946 \mathrm{~cm}^{-1}$ (Figures 5(a)(A) and 5(b)(A)) may be assigned to stretching vibrations of $\mathrm{C}-\mathrm{H}$ groups, while the peaks at $3088 \mathrm{~cm}^{-1}$ and $3250 \mathrm{~cm}^{-1}$ correspond to $\mathrm{N}-\mathrm{H}$ stretching vibrations. After addition of AuNSs to dimethoate (Figure 5(a)(B)), amide I band is shifted towards higher frequency $\left(1652 \mathrm{~cm}^{-1}\right)$, and amide II band splits into two peaks at $1558 \mathrm{~cm}^{-1}$ and $1540 \mathrm{~cm}^{-1}$ [37]. The peaks of $\mathrm{C}-\mathrm{H}$ stretching vibration kept the same position, whereas the peaks of $\mathrm{N}-\mathrm{H}$ stretching vibration appeared at higher wave numbers $3094 \mathrm{~cm}^{-1}$ and $3292 \mathrm{~cm}^{-1}$ compared with corresponding peaks of dimethoate alone. Very similar changes were noticed after addition of NRs to the dimethoate solution, as it can be seen in the $1600-1400 \mathrm{~cm}^{-1}$ range of the spectrum (Figure 5(b)(C)). Two narrow bands appearing at $2850 \mathrm{~cm}^{-1}$ and $2918 \mathrm{~cm}^{-1}$ stem from symmetric and asymmetric stretching vibrations of the $\mathrm{C}-\mathrm{H}$ bonds of CTAB molecule, respectively [36]. The observed spectral changes suggest that interactions between dimethoate and AuNPs occurred [37]. In case of AuNSs obviously dimethoate interacted directly with gold; that is, dimethoate replaced the citrate ions on the surface of the AuNSs [22]. On the other side, it seems that dimethoate interacted with AuNRs via CTAB [36, 38, 39]. These results are in accordance with results obtained spectrophotometrically.

3.5. Adsorption Isotherms Analysis. To quantify the amount of adsorbed dimethoate on $100 \mathrm{mg} / \mathrm{L}$ AuNPs as a function of its concentration in the range from 2 to $1150 \mathrm{mg} / \mathrm{L}$ at $25^{\circ} \mathrm{C}$ the adsorption isotherms were used. The equilibrium of sorption was evaluated by two-parameter and Langmuir and Freundlich isotherm models. The Langmuir isotherm model is the most widely used equation, which assumes monolayer adsorption onto a surface containing a limited number of adsorption sites and without any interactions 


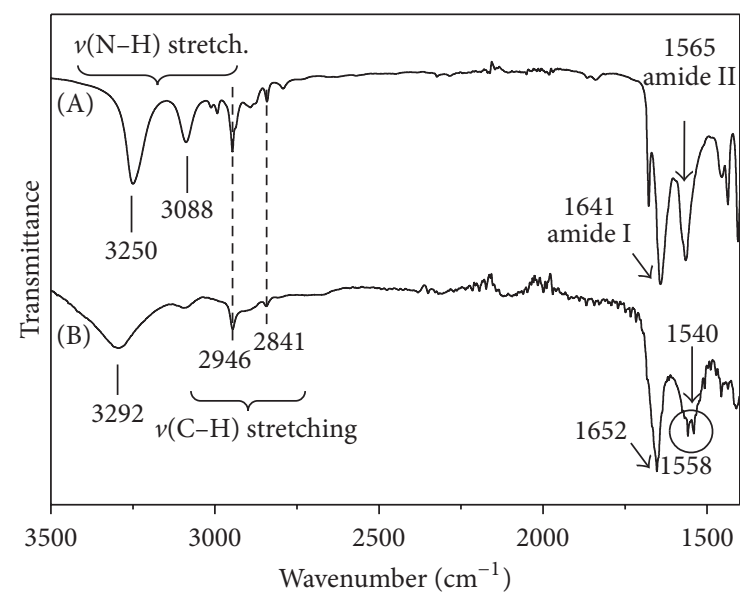

(a)

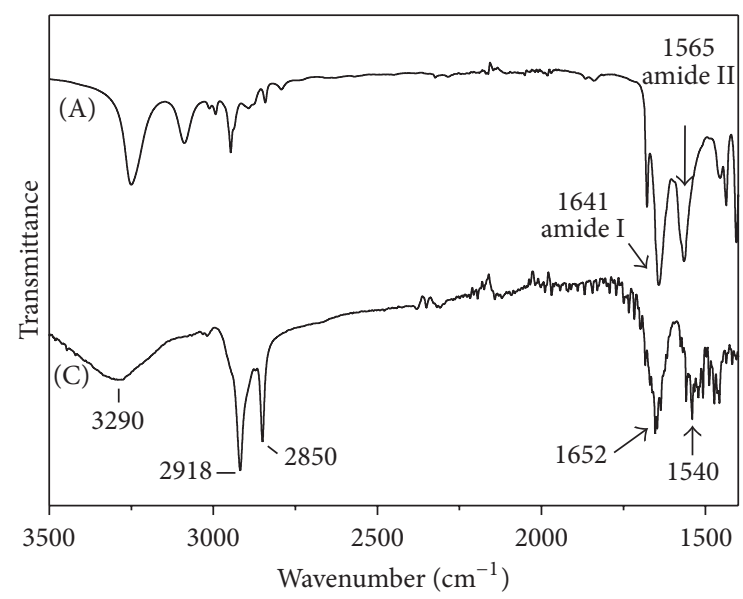

(b)

Figure 5: FTIR spectra of $0.5 \times 10^{-3} \mathrm{M}$ dimethoate $((\mathrm{a})(\mathrm{A}))$ and $((\mathrm{b})(\mathrm{A}))$ alone and in the presence of $((\mathrm{a})(\mathrm{B}))$ AuNSs and ((b)(C)) AuNRs.

between adsorbate molecules on adjacent sites [40, 41]. Its linear form is expressed by the following equation:

$$
\frac{c_{e}}{q_{e}}=\frac{1}{q_{0} K_{L}}+\frac{1}{q_{0}} c_{e}
$$

where $c_{e}(\mathrm{mg} / \mathrm{L})$ is the equilibrium adsorbate concentration, $q_{e}(\mathrm{mg} / \mathrm{g})$ is the amount of adsorbate adsorbed per unit mass of adsorbent, $q_{0}$ is the maximum mass adsorbed under saturation conditions per mass unit of adsorbent $(\mathrm{mg} / \mathrm{g})$, and $K_{L}$ is the equilibrium constant with units of inverse of concentration $c_{e}(\mathrm{~L} / \mathrm{mg}) . q_{0}$ and $K_{L}$ are the Langmuir constants related to the adsorption capacity and the rate of adsorption, respectively. After plotting of $c_{e} / q_{e}$ against $c_{e}$, a straight line was obtained, indicating that the adsorption of dimethoate on the AuNPs follows the Langmuir isotherm. Another important parameter which is a dimensionless constant called the separation factor $\left(R_{L}\right)$ for indicating the type of adsorption using the Langmuir constant $\left(K_{L}\right)$ is evaluated as follows [42]:

$$
R_{L}=\frac{1}{1+K_{L} c_{0}},
$$

where $c_{0}$ is the initial dimethoate concentration $(\mathrm{mg} / \mathrm{L}) . R_{L}$ value indicates the type of adsorption to be either favorable $\left(0<R_{L}<1\right)$, unfavorable $\left(R_{L}>1\right)$, linear $\left(R_{L}=1\right)$, or irreversible $\left(R_{L}=0\right)$.

The Freundlich isotherm model on the other hand takes heterogeneous systems into account and is not restricted to the formation of the monolayer [43]. The linear form of the Freundlich equation is

$$
\ln q_{e}=\ln K_{F}+\left(\frac{1}{n}\right) \ln c_{e}
$$

where $q_{e}$ is the amount adsorbed at equilibrium $(\mathrm{mg} / \mathrm{g})$ and $c_{e}$ is the equilibrium concentration of dimethoate. $K_{F}$ and $n$ are Freundlich constants, where $K_{F}(\mathrm{mg} / \mathrm{g})$ is the adsorption capacity of the adsorbent and with $n$ value giving an indication of how favorable the adsorption process. The slope $1 / n$
TABLE 1: Isotherm parameters for adsorption of dimethoate onto AuNPs.

\begin{tabular}{lccc}
\hline \multirow{2}{*}{ Isotherms } & \multirow{2}{*}{ Parameters } & \multicolumn{2}{c}{ NPs } \\
& & NSs & NRs \\
\hline \multirow{3}{*}{ Langmuir } & $q_{0}(\mathrm{mg} / \mathrm{g})$ & 456 & 57.1 \\
& $K_{L}(\mathrm{~L} / \mathrm{mg})$ & 0.01 & 0.01 \\
& $R_{L}$ & 0.08 & 0.08 \\
$R^{2}$ & 0.960 & 0.999 \\
\hline \multirow{3}{*}{ Freundlich } & $K_{F}\left((\mathrm{mg} / \mathrm{g})(\mathrm{L} / \mathrm{mg})^{1 / n}\right)$ & 17.8 & 1.09 \\
& $1 / n$ & 0.45 & 0.62 \\
& $R^{2}$ & 0.924 & 0.903 \\
\hline
\end{tabular}

ranging between 0 and 1 is a measure of adsorption intensity or surface heterogeneity becoming more heterogeneous as its value gets closer to 0 [44].

The Langmuir and Freundlich isotherms for the adsorption of dimethoate molecules by AuNPs were plotted, and isotherm parameters and correlation coefficients $\left(R^{2}\right)$ were calculated and reported in Table 1 . As shown in Table 1, the Langmuir isotherm with correlation coefficients of 0.960 and 0.999 represents a better fit of experimental data compared to Freundlich isotherm with correlation coefficients of 0.924 and 0.903 , for nanospheres and nanorods, respectively. Also, comparison of experimental adsorption isotherms of dimethoate with nonlinear Langmuir and Freundlich models is presented in Figure 6 for dimethoate adsorption onto AuNSs' and AuNRs' surfaces. Moreover, the maximum adsorption capacity, presented in Table 1 as $q_{0}$ for the Langmuir model, is much higher for nanospheres than for nanorods, that is, $456 \mathrm{mg} / \mathrm{g}$ and $57.1 \mathrm{mg} / \mathrm{g}$, respectively. $R_{L}$ values were less than 1 and greater than 0 (Table 1) indicating favorable and rather irreversible adsorption of dimethoate to both types of nanoparticles. The values of $1 / n$ less than 1 for both types of nanoparticles showed the favorable nature of dimethoate molecule adsorption onto Au nanoparticles (Table 1). The major differences between the two types of 


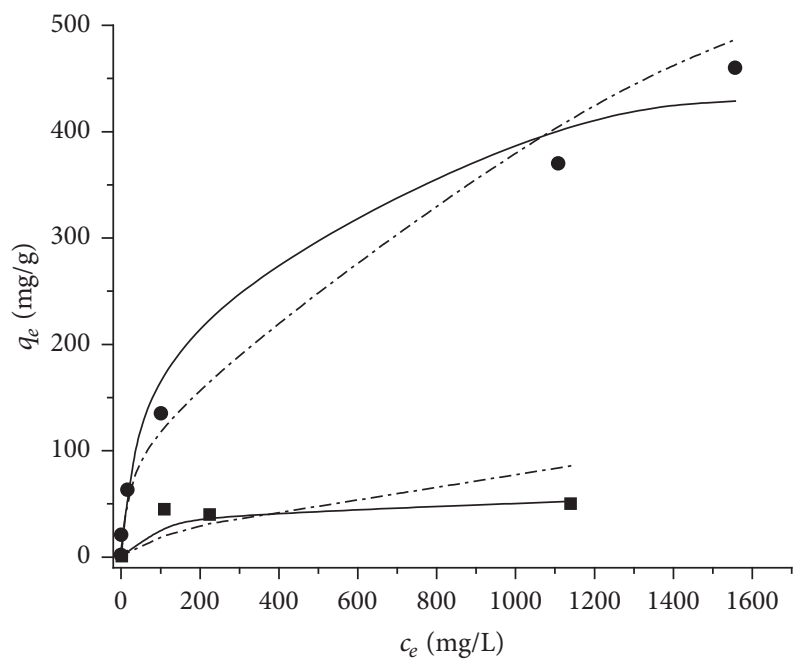

FIgURE 6: Comparison of experimental results of dimethoate adsorbed by AuNPs surfaces with adsorption isotherms. Experimental results are presented: NSs as cycles and NRs as squares, Langmuir model is presented as a solid lines and Freundlich model is presented as dash dot lines.

nanoparticles used are the surface charge and the shape. The surface charge of the citrate-capped nanospheres is negative while the surface of CTAB-capped nanorods is positive in aqueous solution since washing does not remove CTAB from NR surface completely [22, 45]. Regarding different shapes of the two types of nanoparticles and the presence of various facets to which stabilizing ligands bind $[46,47]$ it is expected that adsorption orientation of dimethoate molecules to surface ligands of spheres and rods varies [48]. It is more likely that surface capping has the higher impact on the adsorption capacity of NPs for dimethoate. Even though the specific surface estimated for NSs is almost the same as the specific surface of NRs, $1.2 \times 10^{3}$ and $1.5 \times 10^{3} \mathrm{~cm}^{2} / \mathrm{g}$, respectively, much higher capacity of NSs obviously originated from replacing of citrate anions with dimethoate and their covalent binding to gold NSs' surfaces. Furthermore, as already mentioned, dimethoate molecules are most probably covalently binded only on the NRs ends. Different results have been reported by several earlier works for dimethoate and other organophosphorous pesticides adsorption by various materials. Monolith precursor carbonized at $1000^{\circ} \mathrm{C}$, activated with $\mathrm{KOH}(1: 2)$, and heated at $900^{\circ} \mathrm{C}$ showed adsorption capacity of $0.062 \mathrm{mg} / \mathrm{g}$ for dimethoate [49]. Molecularly imprinted polymers for dimethoate recognition synthesized by the precipitation polymerization technique using methyl methacrylate as the functional monomer and ethylene glycol dimethacrylate (EGDMA) as the cross-linker showed apparent maximum adsorption capacity of $2.4 \mathrm{mg} / \mathrm{g}$ and $12.2 \mathrm{mg} / \mathrm{g}$ for low and high affinity binding sites, respectively [4]. The results of batch adsorption experiments showed that malathion adsorbs on monetite B2 with adsorption capacity of $52 \mathrm{mg} / \mathrm{g}$ [7]. Adsorption capacity of graphene-sand composite prepared from asphalt and sand, for chlorpyrifos, was reported to be $52.6 \mathrm{mg} / \mathrm{g}$ in terms of carbon content [50]. Batch tests carried out for adsorption of malathion

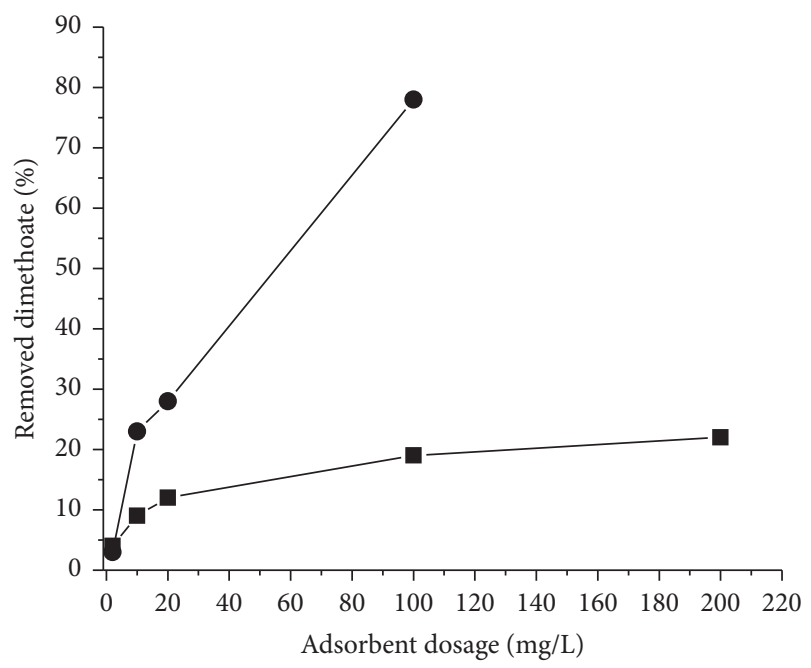

FIGURE 7: Effect of adsorbent dosage level on adsorption of $2.5 \times$ $10^{-4} \mathrm{M}$ dimethoate by NSs (cycles) and NRs (squares).

on granular activated carbon resulted in equilibrium data which fitted well with the Langmuir model and Freundlich model with maximum adsorption capacity of $909.1 \mathrm{mg} / \mathrm{g}$ [51]. Our results are in agreement with the results of previous studies for OPs adsorption by different nanomaterials. Isotherm adsorption data for carbonized nanohemp fibers, activated at $900^{\circ} \mathrm{C}$ with $\mathrm{KOH} /$ carbonized material ratio of $2 / 1$ adsorption of dimethoate, fitted better with Freundlich isotherm and maximum adsorption capacity; that is, $K_{F}$ value was $47(\mathrm{mg} / \mathrm{g})(\mathrm{L} / \mathrm{mg})^{1 / n}$. Also, this material showed very homogenous surface with $1 / n$ value 0.6 [52]. Isotherm data in batch experiment show adsorption capacity of $48 \mathrm{mg} / \mathrm{g}$ for chlorpyrifos adsorption on graphene-sand nanocomposite [53]. The absorption capacity of another nanomaterial, reduced graphene oxide for chlorpyrifos adsorption observed by Maliyekkal et al., was $1200 \mathrm{mg} / \mathrm{g}$ [11]. It is reasonable to claim that AuNSs investigated in this study belong to nanomaterials with high adsorption capacity.

3.6. Removal of Dimethoate from Water by Gold NPs. The effect of adsorbent type and its concentration on dimethoate removal from spiked drinking water was investigated in a batch adsorption technique. The adsorbents (AuNSs and AuNRs) were used at concentration ranging from $2 \mathrm{mg} / \mathrm{L}$ to $200 \mathrm{mg} / \mathrm{L}$. The initial dimethoate concentration was $2.5 \times$ $10^{-4} \mathrm{M}$. From the results depicted in Figure 7 it is very obvious that nanospheres have the advantage over nanorods for dimethoate removal. In each case increase in adsorbent concentration resulted in an increase in percent removal of dimethoate. After certain adsorbent dosage the removal efficiency is not increased so significantly. At $20 \mathrm{mg} / \mathrm{L}$ of adsorbent dosage, the removal of dimethoate was found to be $12 \%$ for nanosphere and $28 \%$ for nanorods. At $100 \mathrm{mg} / \mathrm{L}$ of nanospheres dimethoate removal was $80 \%$ and for the same nanorods dosage dimethoate removal efficiency achieved was $19 \%$. Since concentration of unadsorbed dimethoate at dosage level of $200 \mathrm{mg} / \mathrm{L}$ for nanospheres could not be detected by 
UPLC technique, it is evident that adsorption of dimethoate was between $80 \%$ and $100 \%$. The dosage of $200 \mathrm{mg} / \mathrm{L}$ of nanorods adsorbed $22 \%$ of dimethoate, so it is clear that for nanorods maximum removal efficacy was significantly lower than the one of nanospheres and was achieved at $100 \mathrm{mg} / \mathrm{L}$ of nanorods. The results for dimethoate removal are in concordance with maximum adsorption capacity values determined in this work $456 \mathrm{mg} / \mathrm{g}$ and $57.1 \mathrm{mg} / \mathrm{g}$ for NSs and NRs, respectively. Previously it was published that various organophosphate pesticides malathion, parathion, chlorpyrifos, and dimethoate were removed from simulated contaminated water in a single step using spherical gold nanoparticles produced on the surface of Rhizopus oryzae with efficacy of $85-99 \%$ [14]. Also, 85-99\% of parathion and chloropyrifos were removed with synthesized nanosilver bioconjugate synthesized through in situ reduction of silver nitrate by a fungal strain of Rhizopus oryzae [15]. Also it was shown that bare gold and silver nanoparticles and those supported on alumina are excellent systems for the removal of the organophosphorous pesticides, chlorpyrifos and malathion, from water [17]. Regarding all the results of this study we can assume that although nanorods possess greater potential as biological and medicinal tools for imaging, sensing, and nanotechnology-driven therapeutics thanks to their morphology over their spherical counterparts [54-56] nanospheres are more potent for adsorption of dimethoate from water. It should be emphasized that higher potency of NSs for dimethoate adsorption originated from replacing of citrate anions with dimethoate and their covalent binding to gold NSs' surfaces and not from NPs morphology.

\section{Conclusion}

The adsorption of organophosphate pesticide dimethoate on AuNSs and AuNRs was investigated in aqueous solution at room temperature for 24 hours, using UV-Vis spectrophotometry, TEM, AFM, and FTIR. It was shown that dimethoate adsorbed on both AuNPs. Its adsorption onto AuNSs was followed by NPs aggregation and eventually their stabilization. That was not the case with AuNRs. The Langmuir adsorption isotherm was found to have the best fit to the experimental data which suggests that monolayer adsorption on a homogeneous surface is the predominant process. However, multilayer adsorption cannot be ruled out as a good $1 / n$ value was obtained for the Freundlich model. Nanospheres showed much higher adsorption capacity compared to nanorods regardless of which isotherm model was used. Consequently, we showed that NSs were more efficient in dimethoate removal from water compared to NRs.

\section{Competing Interests}

The authors declare that they have no competing interests regarding the publication of this paper.

\section{Acknowledgments}

This work was financially supported by the Ministry of Education, Science and Technological Development of the
Republic of Serbia, Project no. 172023. This study was performed in the context of the European COST Action MP1302 Nanospectroscopy.

\section{References}

[1] M. S. Bootharaju and T. Pradeep, "Understanding the degradation pathway of the pesticide, chlorpyrifos by noble metal nanoparticles," Langmuir, vol. 28, no. 5, pp. 2671-2679, 2012.

[2] Y. Lv, Z. Lin, W. Feng, X. Zhou, and T. Tan, "Selective recognition and large enrichment of dimethoate from tea leaves by molecularly imprinted polymers," Biochemical Engineering Journal, vol. 36, no. 3, pp. 221-229, 2007.

[3] J. S. Van Dyk and B. Pletschke, "Review on the use of enzymes for the detection of organochlorine, organophosphate and carbamate pesticides in the environment," Chemosphere, vol. 82, no. 3, pp. 291-307, 2011.

[4] J.-J. Du, R.-X. Gao, H. Yu, X.-J. Li, and H. Mu, "Selective extraction of dimethoate from cucumber samples by use of molecularly imprinted microspheres," Journal of Pharmaceutical Analysis, vol. 5, no. 3, pp. 200-206, 2015.

[5] K. Simeonidis, S. Mourdikoudis, E. Kaprara, M. Mitrakas, and L. Polavarapu, "Inorganic engineered nanoparticles in drinking water treatment: a critical review," Environmental Science: Water Research \& Technology, vol. 2, no. 1, pp. 43-70, 2016.

[6] L. Clausen, I. Fabricius, and L. Madsen, "Adsorption of pesticides onto quartz, calcite, kaolinite, and $\alpha$-alumina," Journal of Environmental Quality, vol. 30, no. 3, pp. 846-857, 2001.

[7] M. M. Mirković, T. D. L. Pašti, A. M. Došen et al., "Adsorption of malathion on mesoporous monetite obtained by mechanochemical treatment of brushite," RSC Advances, vol. 6, no. 15, pp. 12219-12225, 2016.

[8] E. Ayranci and N. Hoda, "Adsorption kinetics and isotherms of pesticides onto activated carbon-cloth," Chemosphere, vol. 60, no. 11, pp. 1600-1607, 2005.

[9] P. Wang, Y. Yin, Y. Guo, and C. Wang, "Preponderant adsorption for chlorpyrifos over atrazine by wheat straw-derived biochar: experimental and theoretical studies," RSC Advances, vol. 6, no. 13, pp. 10615-10624, 2016.

[10] T. D. Lazarević-Pašti, I. A. Pašti, B. Jokić, B. M. Babić, and V. M. Vasić, "Heteroatom-doped mesoporous carbons as efficient adsorbents for removal of dimethoate and omethoate from water," RSC Advances, vol. 6, no. 67, pp. 62128-62139, 2016.

[11] S. M. Maliyekkal, T. S. Sreeprasad, D. Krishnan et al., "Graphene: a reusable substrate for unprecedented adsorption of pesticides," Small, vol. 9, no. 2, pp. 273-283, 2013.

[12] T. Pradeep and Anshup, "Detection and extraction of pesticides from drinking water using nanotechnologies," in Nanotechnology Applications for Clean Water, N. Savage, M. Diallo, J. Duncan, A. Street, and R. Sustich, Eds., pp. 191-212, William Andrew Inc, Boston, Mass, USA, 2009.

[13] T. Pradeep and Anshup, "Noble metal nanoparticles for water purification: a critical review," Thin Solid Films, vol. 517, no. 24, pp. 6441-6478, 2009.

[14] S. K. Das, A. R. Das, and A. K. Guha, "Gold nanoparticles: microbial synthesis and application in water hygiene management," Langmuir, vol. 25, no. 14, pp. 8192-8199, 2009.

[15] S. K. Das, M. M. R. Khan, A. K. Guha, A. R. Das, and A. B. Mandal, "Silver-nano biohybride material: synthesis, characterization and application in water purification," Bioresource Technology, vol. 124, pp. 495-499, 2012. 
[16] B. L. Brenner, S. Markowitz, M. Rivera et al., "Integrated pest management in an urban community: a successful partnership for prevention," Environmental Health Perspectives, vol. 111, no. 13, pp. 1649-1653, 2003.

[17] A. S. Nair and T. Pradeep, "Extraction of chlorpyrifos and malathion from water by metal nanoparticles," Journal of Nanoscience and Nanotechnology, vol. 7, no. 6, pp. 1871-1877, 2007.

[18] R. Gupta and G. U. Kulkarni, "Removal of organic compounds from water by using a gold nanoparticle-poly(dimethylsiloxane) nanocomposite foam," ChemSusChem: Chemistry \& Sustainability, Energy and Materials, vol. 4, no. 6, pp. 737-743, 2011.

[19] C. Yu, Z. Zhu, Q. Wang, W. Gu, N. Bao, and H. Gu, "A disposable indium-tin-oxide sensor modified by gold nanorod-chitosan nanocomposites for the detection of $\mathrm{H}_{2} \mathrm{O}_{2}$ in cancer cells," Chemical Communications, vol. 50, no. 55, pp. 7329-7331, 2014.

[20] C. Wang, Z. Ma, T. Wang, and Z. Su, "Synthesis, assembly, and biofunctionalization of silica-coated gold nanorods for colorimetric biosensing," Advanced Functional Materials, vol. 16, no. 13, pp. 1673-1678, 2006.

[21] S. E. Lohse and C. J. Murphy, "Applications of colloidal inorganic nanoparticles: from medicine to energy," Journal of the American Chemical Society, vol. 134, no. 38, pp. 15607-15620, 2012.

[22] A. Vujačić, V. Vasić, M. Dramićanin et al., "Fluorescence quenching of $5,5^{\prime}$-disulfopropyl-3,3'-dichlorothiacyanine dye adsorbed on gold nanoparticles," Journal of Physical Chemistry C, vol. 117, no. 13, pp. 6567-6577, 2013.

[23] U. Bogdanović, V. V. Vodnik, S. P. Ahrenkiel, M. Stoiljković, G. Ćirić-Marjanović, and J. M. Nedeljković, "Interfacial synthesis and characterization of gold/polyaniline nanocomposites," Synthetic Metals, vol. 195, pp. 122-131, 2014.

[24] B. Nikoobakht and M. A. El-Sayed, "Preparation and growth mechanism of gold nanorods (NRs) using seed-mediated growth method," Chemistry of Materials, vol. 15, no. 10, pp.19571962, 2003.

[25] A. B. Witte, A. N. Leistra, P. T. Wong et al., "Atomic force microscopy probing of receptor-nanoparticle interactions for riboflavin receptor targeted gold-dendrimer nanocomposites," Journal of Physical Chemistry B, vol. 118, no. 11, pp. 2872-2882, 2014.

[26] X. Zhou, Y. Zhang, F. Zhang et al., "Hierarchical ordering of amyloid fibrils on the mica surface," Nanoscale, vol. 5, no. 11, pp. 4816-4822, 2013.

[27] A. K. Bhattacharya, T. K. Naiya, S. N. Mandal, and S. K. Das, "Adsorption, kinetics and equilibrium studies on removal of $\mathrm{Cr}(\mathrm{VI})$ from aqueous solutions using different low-cost adsorbents," Chemical Engineering Journal, vol. 137, no. 3, pp. 529-541, 2008.

[28] J. H. Yoon, J. S. Park, and S. Yoon, “Time-dependent and symmetry-selective charge-transfer contribution to sers in gold nanoparticle aggregates," Langmuir, vol. 25, no. 21, pp. 1247512480, 2009.

[29] R. Sardar, T. B. Heap, and J. S. Shumaker-Parry, "Versatile solid phase synthesis of gold nanoparticle dimers using an asymmetric functionalization approach," Journal of the American Chemical Society, vol. 129, no. 17, pp. 5356-5357, 2007.

[30] S.-Y. Lin, Y.-T. Tsai, C.-C. Chen, C.-M. Lin, and C.-H. Chen, "Two-step functionalization of neutral and positively charged thiols onto citrate-stabilized Au nanoparticles," The Journal of Physical Chemistry B, vol. 108, no. 7, pp. 2134-2139, 2004.
[31] M. R. Ivanov, H. R. Bednar, and A. J. Haes, "Investigations of the mechanism of gold nanoparticle stability and surface functionalization in capillary electrophoresis," ACS Nano, vol. 3, no. 2, pp. 386-394, 2009.

[32] T. Kim, K. Lee, M.-S. Gong, and S.-W. Joo, "Control of gold nanoparticle aggregates by manipulation of interparticle interaction," Langmuir, vol. 21, no. 21, pp. 9524-9528, 2005.

[33] R. A. Sperling and W. J. Parak, "Surface modification, functionalization and bioconjugation of colloidal inorganic nanoparticles," Philosophical Transactions of the Royal Society A: Mathematical, Physical and Engineering Sciences, vol. 368, no. 1915, pp. 1333-1383, 2010.

[34] M. Gluodenis and C. A. Foss Jr., "The effect of mutual orientation on the spectra of metal nanoparticle rod-rod and rod-sphere pairs," Journal of Physical Chemistry B, vol. 106, no. 37, pp. 9484-9489, 2002.

[35] N. Thioune, N. Lidgi-Guigui, M. Cottat et al., "Study of gold nanorods-protein interaction by localized surface plasmon resonance spectroscopy," Gold Bulletin, vol. 46, no. 4, pp. 275281, 2013.

[36] J. Vonnemann, N. Beziere, C. Böttcher et al., "Polyglycerolsulfate functionalized gold nanorods as optoacoustic signal nanoamplifiers for in vivo bioimaging of rheumatoid arthritis," Theranostics, vol. 4, no. 6, pp. 629-641, 2014.

[37] K. Esumi and K. Torigoe, "Preparation and characterization of noble metal nanoparticles using dendrimers as protective colloids," in Progress in Colloid and Polymer Science, F. Kremer and G. Lagaly, Eds., vol. 117, pp. 80-88, Springer, Heidelberg, Germany, 2001.

[38] J. Lim, N.-E. Lee, E. Lee, and S. Yoon, "Surface modification of citrate-capped gold nanoparticles using CTAB micelles," Bulletin of the Korean Chemical Society, vol. 35, no. 8, pp. 25672569, 2014.

[39] A. M. Alkilany, P. K. Nagaria, M. D. Wyatt, and C. J. Murphy, "Cation exchange on the surface of gold nanorods with a polymerizable surfactant: polymerization, stability, and toxicity evaluation," Langmuir, vol. 26, no. 12, pp. 9328-9333, 2010.

[40] I. Langmuir, "The adsorption of gases on plane surfaces of glass, mica and platinum," Journal of the American Chemical Society, vol. 40, no. 9, pp. 1361-1403, 1918.

[41] S. Chakravarty, V. Dureja, G. Bhattacharyya, S. Maity, and S. Bhattacharjee, "Removal of arsenic from groundwater using low cost ferruginous manganese ore," Water Research, vol. 36, no. 3, pp. 625-632, 2002.

[42] K. R. Hall, L. C. Eagleton, A. Acrivos, and T. Vermeulen, "Poreand solid-diffusion kinetics in fixed-bed adsorption under constant-pattern conditions," Industrial \& Engineering Chemistry Fundamentals, vol. 5, no. 2, pp. 212-223, 1966.

[43] H. M. F. Freundlich, "Uber die adsorption in losungen," Zeitschrift für Physikalische Chemie, vol. 57, pp. 385-470, 1906.

[44] F. Haghseresht and G. Q. Lu, "Adsorption characteristics of phenolic compounds onto coal-reject-derived adsorbents," Energy \& Fuels, vol. 12, no. 6, pp. 1100-1107, 1998.

[45] J. S. Bozich, S. E. Lohse, M. D. Torelli, C. J. Murphy, R. J. Hamers, and R. D. Klaper, "Surface chemistry, charge and ligand type impact the toxicity of gold nanoparticles to Daphnia magna," Environmental Science: Nano, vol. 1, no. 3, pp. 260-270, 2014.

[46] W. P. Wuelfing, S. M. Gross, D. T. Miles, and R. W. Murray, "Nanometer gold clusters protected by surface-bound monolayers of thiolated poly(ethylene glycol) polymer electrolyte," Journal of the American Chemical Society, vol. 120, no. 48, pp. 12696-12697, 1998. 
[47] B. Nikoobakht and M. A. El-Sayed, "Evidence for bilayer assembly of cationic surfactants on the surface of gold nanorods," Langmuir, vol. 17, no. 20, pp. 6368-6374, 2001.

[48] S. Khan, A. Gupta, N. C. Verma, and C. K. Nandi, "Kinetics of protein adsorption on gold nanoparticle with variable protein structure and nanoparticle size," The Journal of Chemical Physics, vol. 143, no. 16, Article ID 164709, 2015.

[49] M. Vukčević, A. Kalijadis, B. Babić, Z. Laušević, and M. Laušević, "Influence of different carbon monolith preparation parameters on pesticide adsorption," Journal of the Serbian Chemical Society, vol. 78, no. 10, pp. 1617-1632, 2013.

[50] T. S. Sreeprasad, S. S. Gupta, S. M. Maliyekkal, and T. Pradeep, "Immobilized graphene-based composite from asphalt: facile synthesis and application in water purification," Journal of Hazardous Materials, vol. 246-247, pp. 213-220, 2013.

[51] A. Jusoh, W. J. H. Hartini, N. Ali, and A. Endut, "Study on the removal of pesticide in agricultural run off by granular activated carbon," Bioresource Technology, vol. 102, no. 9, pp. 5312-5318, 2011.

[52] M. M. Vukčević, A. M. Kalijadis, T. M. Vasiljević, B. M. Babić, Z. V. Laušević, and M. D. Laušević, "Production of activated carbon derived from waste hemp (Cannabis sativa) fibers and its performance in pesticide adsorption," Microporous and Mesoporous Materials, vol. 214, pp. 156-165, 2015.

[53] S. S. Gupta, T. S. Sreeprasad, S. M. Maliyekkal, S. K. Das, and T. Pradeep, "Graphene from sugar and its application in water purification," ACS Applied Materials \& Interfaces, vol. 4, no. 8, pp. 4156-4163, 2012.

[54] J. Stone, S. Jackson, and D. Wright, "Biological applications of gold nanorods," Wiley Interdisciplinary Reviews: Nanomedicine and Nanobiotechnology, vol. 3, no. 1, pp. 100-109, 2011.

[55] T. H. D. Nguyen, Z. Zhang, A. Mustapha, H. Li, and M. Lin, "Use of graphene and gold nanorods as substrates for the detection of pesticides by surface enhanced raman spectroscopy," Journal of Agricultural and Food Chemistry, vol. 62, no. 43, pp. 1044510451, 2014.

[56] Y. V. Kaneti, C. Chen, M. Liu et al., "Carbon-coated gold nanorods: a facile route to biocompatible materials for photothermal applications," ACS Applied Materials \& Interfaces, vol. 7, no. 46, pp. 25658-25668, 2015. 

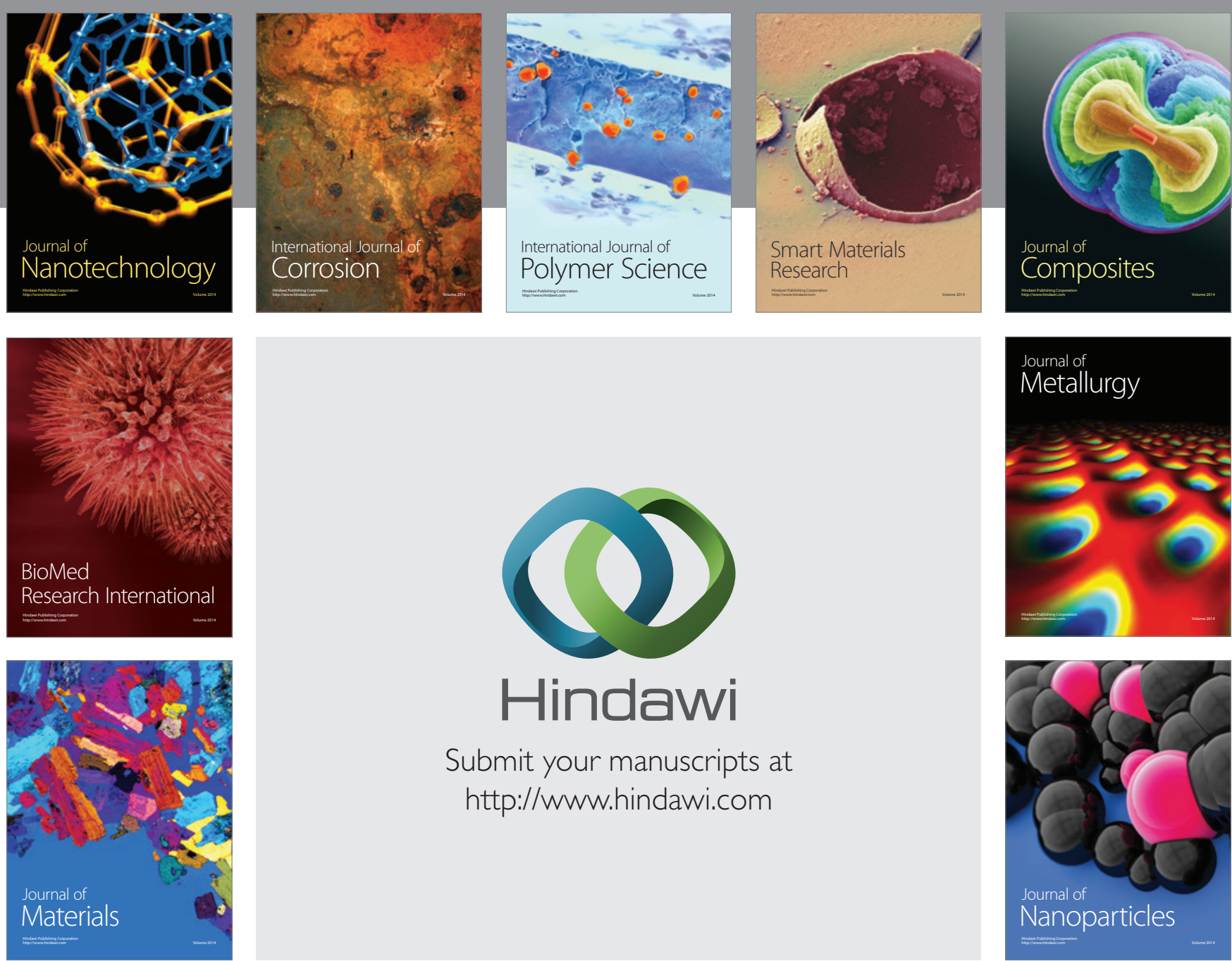

\section{Hindawi}

Submit your manuscripts at

http://www.hindawi.com

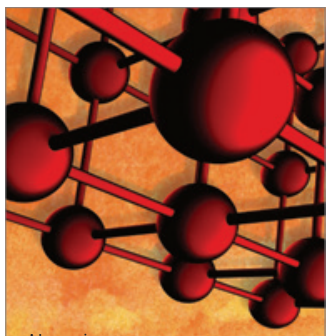

Materials Science and Engineering
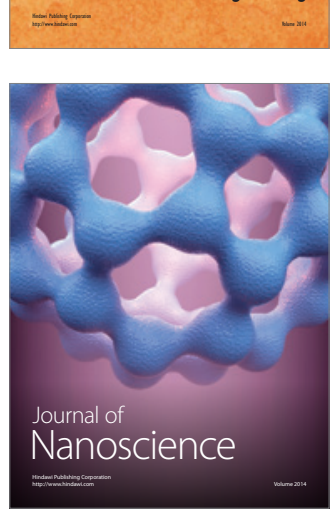
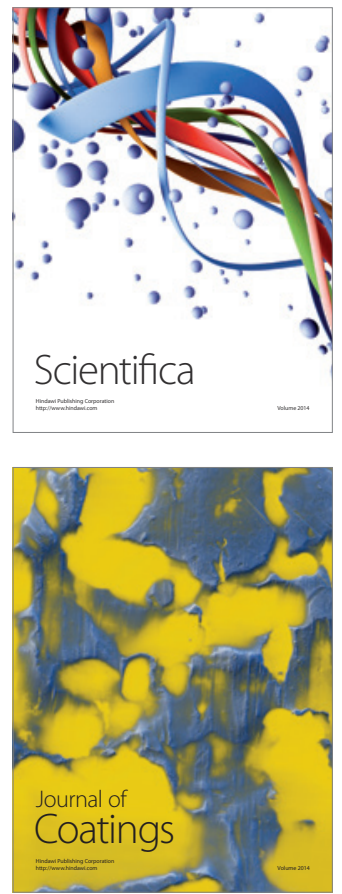
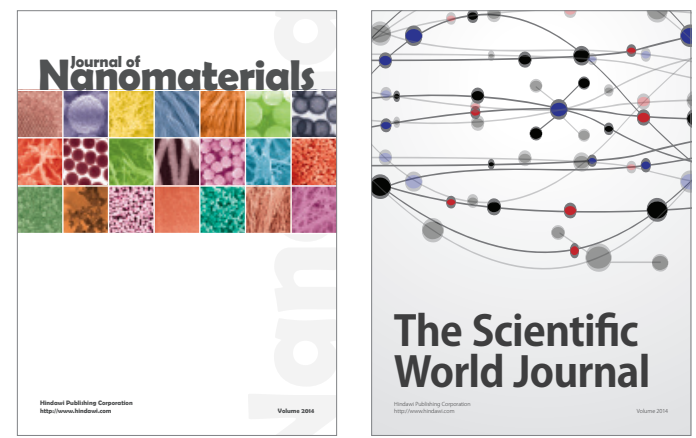

The Scientific World Journal
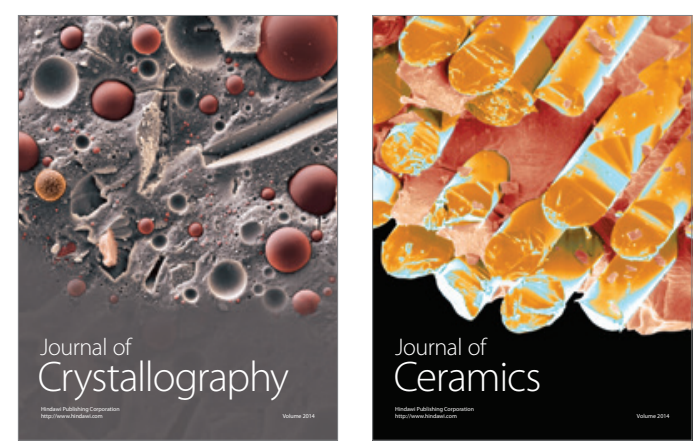
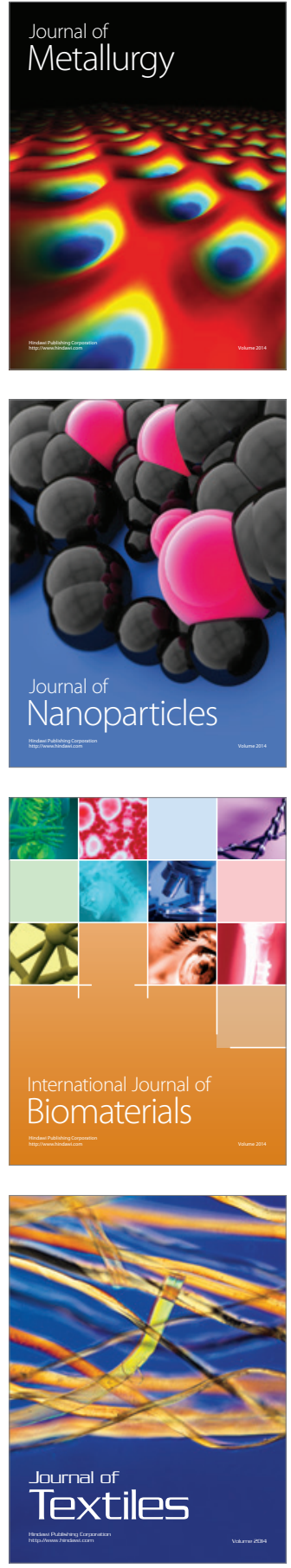